\title{
ORIGINAL ARTICLE Vitamin D deficiency in Swiss elite wheelchair athletes
}

\author{
JL Flueck, K Hartmann, M Strupler and C Perret
}

Study design: This is a retrospective analysis of total serum 25-hydroxyvitamin D (25[OH]D) in Swiss elite wheelchair athletes. Objectives: The aim was to investigate the occurrence of vitamin D deficiency in Swiss elite wheelchair athletes over the whole year and to detect differences between winter and summer months, and between indoor and outdoor athletes.

Setting: This study was conducted in Switzerland.

Methods: A total of 164 blood samples from 72 Swiss elite wheelchair athletes (mean \pm s.d.: age $32 \pm 13$ years) were analyzed for total serum 25[OH]D. All participants were members of the national team in their discipline. The following disciplines have been included: rugby, athletics, cycling, tennis, ski alpine, curling and basketball. According to general guidelines, insufficient vitamin $\mathrm{D}$ status was defined between 50 and $75 \mathrm{nmol} \mathrm{I}^{-1}$, deficiency below $50 \mathrm{nmoll}^{-1}$ and severe deficiency below $27.5 \mathrm{nmol} \mathrm{I-1}$.

Results: In all, $73.2 \%$ of all samples showed an insufficiency/deficiency in vitamin D status. Total serum 25[OH]D was significantly higher during summer compared with winter months $\left(69.5 \pm 21.4 \mathrm{nmol} \mathrm{I}^{-1}\right.$ vs $\left.51.5 \pm 21.9 \mathrm{nmol} \mathrm{I}^{-1} ; P<0.001\right)$. Indoor sports showed a higher amount of vitamin D insufficiency/deficiency (80.9\%) than outdoor sports (70.1\%), with a significantly higher 25[OH]D concentration in outdoor sports $(P=0.042)$.

Conclusion: A high percentage of vitamin D deficiency was found among Swiss elite wheelchair athletes. Conclusively, we recommend supplementation with vitamin D-especially during winter-to prevent a deficiency and an impairment of performance.

Spinal Cord (2016) 54, 991-995; doi:10.1038/sc.2016.33; published online 15 March 2016

\section{INTRODUCTION}

In the past few years, vitamin D intake, status and supplementation were of increasing interest. Quite a few studies showed a relatively high prevalence for vitamin D insufficiency or deficiency among different population groups such as healthy able-bodied adults, children, newborn, elderly, as well as in athletes and subjects with a spinal cord injury. ${ }^{1-7}$ An inadequate intake of vitamin D-containing food sources or an insufficient exposure of the skin to sunlight can lead to such a vitamin D deficiency. Dark skin, sun exposure at dawn and dusk, insufficient surface area of the skin exposed to sun, cloudy weather, Northern latitudes, as well as sun-block lotions might be examples for such an insufficient sun exposure. ${ }^{8}$ Vitamin D deficiency is linked to several significant diseases such as diabetes, depression, ${ }^{9,10}$ osteomalacia, ${ }^{11}$ cardiovascular diseases, ${ }^{12}$ hypertension, ${ }^{13}$ multiple sclerosis, Parkinson's and Alzheimer's disease, ${ }^{14}$ cancer ${ }^{15,16}$ and metabolic syndrome. ${ }^{17}$ In addition, it impairs bone health, ${ }^{18}$ muscle function ${ }^{19}$ and possibly also exercise performance. ${ }^{8,20}$ Even healthy young adults and athletes are not excluded from such a deficiency or insufficiency. ${ }^{1,21}$ In an elderly population, a reduction of falls by $20 \%$ seemed to appear; supplementation with vitamin $\mathrm{D}^{22}$ and muscle power and force seemed to be associated with vitamin D levels in adolescent girls. ${ }^{23}$ In addition, several studies were performed investigating the effects of ultraviolet radiation on athletic performance, and positive results were found compared with controls. ${ }^{20}$ Therefore, the role of vitamin $\mathrm{D}$ in neuromuscular and skeletal function had to be taken into account when talking about exercise performance.
As mentioned before, individuals suffering from a chronic spinal cord injury were found to show a high occurrence of vitamin D insufficiency/deficiency. ${ }^{4,6}$ The reasons for this were less sun exposure because of bedrest and immobility, covering of body surface with clothing because of altered thermoregulation and sensitivity of the skin below the lesion level. Another study, investigating acute spinal cord injury, showed a prevalence of $93 \%$ of inadequacy or even severe deficiency. ${ }^{5}$ To our knowledge, only one study investigated the vitamin D status in wheelchair elite athletes. ${ }^{24}$ Authors showed a significant increase in total serum vitamin D levels from November until March under supplementation. In addition, wheelchair-bound athletes had significantly lower vitamin D levels compared with mobile paralympians. This study only assessed vitamin D status before (November) and after (March) supplementation. Therefore, knowledge about vitamin D levels over the whole year in wheelchair elite athletes is still lacking. However, this knowledge about the variation of vitamin D status during the whole year seems to be of interest to avoid vitamin D deficiency and its possible negative consequences for exercise performance. Thus, our aim was to investigate the vitamin D levels in all of our Swiss paralympic national team members from several different sports disciplines throughout the whole year. For us, it was very important to see the variation of vitamin $\mathrm{D}$ levels over the whole year for every single month separately. In addition, comparison between summer and winter, and between indoor and outdoor sports should give more insight and help to give more accurate recommendations in terms of vitamin $\mathrm{D}$ supplementation in our specific population.

Institute of Sports Medicine, Swiss Paraplegic Centre Nottwil, Nottwil, Switzerland

Correspondence: JL Flueck, Institute of Sports Medicine Nottwil, Swiss Paraplegic Centre, Guido A Zaech Street 4, Nottwil, Lucerne CH-6207, Switzerland. E-mail: joelle.flueck@paraplegie.ch

Received 26 August 2015; revised 15 January 2016; accepted 12 February 2016; published online 15 March 2016 


\section{MATERIALS AND METHODS}

A total of 164 blood samples of 51 male (mean \pm s.d., age: $34 \pm 13$ years; height: $174 \pm 10 \mathrm{~cm}$; weight: $70 \pm 13 \mathrm{~kg}$ ) and 21 female (mean \pm s.d., age: $31 \pm 13$ years; height: $162 \pm 12 \mathrm{~cm}$; weight: $56 \pm 13 \mathrm{~kg}$ ) Swiss elite wheelchair athletes were analyzed to measure total serum 25 -hydroxyvitamin D $(25[\mathrm{OH}] \mathrm{D})$. Three subjects were amputees but wheelchair-bound during exercise and also during daily life. All of the Swiss elite wheelchair athletes had to visit the Institute of the Sports Medicine in Nottwil once per year for their yearly medical checkup and for performance testing. Before the medical checkup, a blood sample was taken to analyze various blood parameters including the total serum $25[\mathrm{OH}] \mathrm{D}$. The study did not exclude subjects who were treated against vitamin D deficiency or osteoporosis. All athletes from the national team in every sports discipline were included in this retrospective data analysis. They competed in wheelchair rugby, basketball, athletics, tennis, paracycling, ski alpine and curling. Data were recorded between 2011 and 2014.

\section{Blood sampling and analysis}

Sampling was undertaken across the whole year depending on the month when the athletes had to perform exercise testing and the medical checkup. As our athletes competed in different sports disciplines, the months of performance testing varied between the athletes depending on their season of competition and on their off-season time period. According to general guidelines, ${ }^{25}$ the level of insufficiency was set at $<75 \mathrm{nmol}^{-1}$ of total serum 25[OH]D concentration, whereas deficiency was defined as $<50 \mathrm{nmol}^{-1}$ and severe deficiency as $<27.5 \mathrm{nmol}^{-1}$.

Blood samples were taken from the antecubital vein. Samples were filled in 4.7 -ml tubes (S-Monovette, Serum-Gel, Sarestedt, Nümbrecht, Germany) and immediately stored in an aluminum foil to protect the sample from sunlight exposure. Samples were taken to the internal laboratory as soon as possible, where they were centrifuged $\left(20^{\circ} \mathrm{C}, 10 \mathrm{~min}, 3000\right.$ r.p.m. $)$ and stored at $-24^{\circ} \mathrm{C}$ for later analysis. All samples were analyzed using an automated benchtop immunoanalyzer (VIDAS, bioMérieux, Marcy l'Etoile, France), which is based on enzyme-linked fluorescent assay technology.

\section{Statistical analysis}

All statistical analyses were conducted using SPSS Version 20.0 (IBM, Somers, New York, USA), and significance level was set at 0.05 throughout. Data were tested for normal distribution using the Kolmogorov-Smirnov test and the Q-Q plot. The results indicated a normal distribution, and therefore mean and s.d. were used to display the age and the total serum 25[OH]D. Descriptive statistics was used to describe the study sample (percentage, mean, s.d. and number of samples). To compare total serum 25[OH]D between different

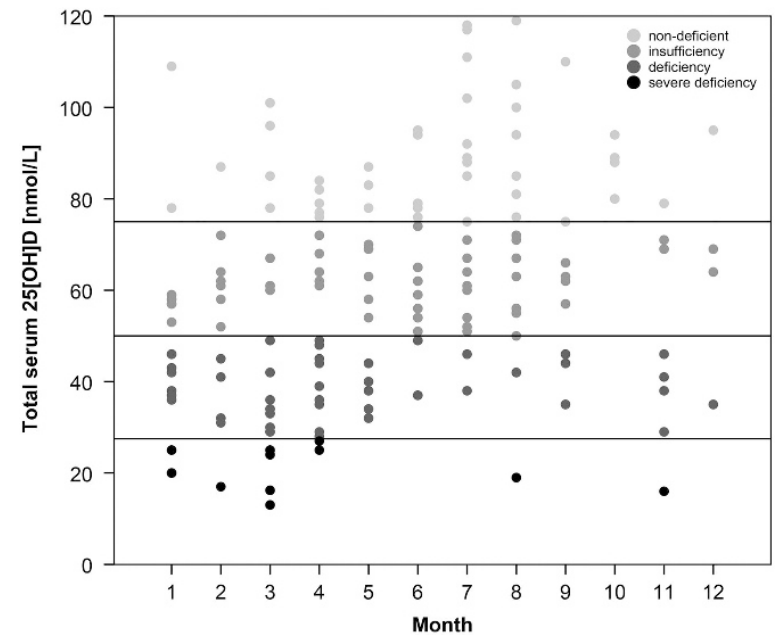

Figure 1 Total serum 25[OH]D of each samples arranged month per month and classified into nondeficient $\left(>75 \mathrm{nmoll}^{-1}\right)$, insufficient $\left(50-75 \mathrm{nmol} \mathrm{I}^{-1}\right)$, deficient $\left(27.5-49.9 \mathrm{nmoll}^{-1}\right)$ and severely deficient $\left(<27.5 \mathrm{nmol} \mathrm{I}^{-1}\right)$. groups (for example, gender, impairment level, impairment extent, season and type of activity), a two-sample $t$-test was applied. Summer was defined as months from May to October, and winter was defined as months from November to April.

\section{Statement of ethics}

We certify that all applicable institutional and governmental regulations concerning the ethical use of health-related data were followed during the course of this research. The study met all ethical standards following the Helsinki Declaration. ${ }^{26}$ General consent for retrospective analysis was signed by all Swiss elite wheelchair athletes.

\section{RESULTS}

A total of 109 (66.5\%) samples from male and 55 (33.5\%) samples from female athletes were analyzed. Most of the samples were drawn from paraplegic subjects $(82.4 \%)$ and only a small amount from tetraplegic subjects $(14.6 \%)$. Five samples $(3.0 \%)$ were taken from amputees. Our data showed that total serum 25[OH]D was below $75 \mathrm{nmol}^{-1}$ in $73.2 \%(n=120)$ of our samples and were classified as vitamin $\mathrm{D}$ deficient/insufficient. The other $26.8 \%$ of the samples showed no vitamin $\mathrm{D}$ deficiency with a vitamin $\mathrm{D}$ level above $75 \mathrm{nmoll}^{-1}$. During summer months (May to October), 30 samples (38.5\%) showed no deficiency, whereas the other 48 samples $(61.5 \%)$ showed an insufficiency or even a deficiency. During winter months (November to April), the occurrence of an insufficient or deficient vitamin D status was much higher (72 samples, 83.7\%). This means that only $14(16.3 \%)$ of the samples tested during winter months were nondeficient. All samples were illustrated month per month in Figure 1 classified according to the four different categories of deficiency to show the variation in vitamin $\mathrm{D}$ levels over the whole year.

During the whole year, 44 samples showed no deficiency with a mean ( \pm s.d.) of $89.8 \pm 12.6 \mathrm{nmol}^{-1}$. In all, $37.2 \%(n=61)$ showed an insufficiency with a mean of $62.0 \pm 6.4 \mathrm{nmol}^{-1}$. Almost one-third of the samples $(28.7 \% ; n=47)$ were characterized as deficient with a mean of $38.7 \pm 6.3 \mathrm{nmoll}^{-1}$. Only 12 samples (7.3\%) were below $27.5 \mathrm{nmoll}^{-1}$ with a mean of $20.6 \pm 4.5 \mathrm{nmoll}^{-1}$ and therefore defined as severely deficient. Table 1 showed the amount of samples for each level of deficiency during winter and summer months, respectively.

The comparison of different group analysis is shown in Table 2. Comparisons were made for data over the whole year, as well as for winter and summer months separately. In indoor sports, $80.9 \%$ of all tested samples showed a deficiency. In contrast, only $70.1 \%$ of the tested samples showed a deficiency in outdoor sports. Indoor sports showed more severe $(5.1 \%)$ and deficient $(23.4 \%)$ samples compared with outdoor sports ( $1.4 \%$ and $16.9 \%$, respectively). In Table 3, samples were classified into one of the four levels of vitamin D deficiency month per month.

Table 1 Vitamin D status compared between summer (May to October) and winter (November to April) months

\begin{tabular}{lcc}
\hline Classification of vitamin D status & Winter (N/\%) & Summer (N/\%) \\
\hline Nondeficient & $14 / 16.3$ & $30 / 38.5$ \\
Insufficient & $27 / 31.4$ & $34 / 43.6$ \\
Deficient & $34 / 39.4$ & $13 / 16.7$ \\
Severely deficient & $11 / 12.8$ & $1 / 1.3$ \\
\hline
\end{tabular}

Abbreviations: $\mathrm{N}$, number of samples; \%, percentage of all samples during this season. 
Table 2 Comparison of total serum 25[OH]D between different groups

\begin{tabular}{lll}
\hline Groups & Whole year & Summer
\end{tabular}

\section{Gender}

Male

Female

$$
\begin{gathered}
60.4 \pm 23.2 \\
(N=108) \\
\text { Range: } 13-119 \\
59.2 \pm 24.1 \\
(N=55) \\
\text { Range: } 16-118
\end{gathered}
$$

\section{Impairment level}

$\begin{array}{cc}\text { Paraplegia } & 60.6 \pm 22.6 \\ & (N=135) \\ & \text { Range: } 16-119 \\ \text { Tetraplegia } & 58.1 \pm 29.2 \\ & (N=24) \\ & \text { Range: } 13-110\end{array}$

Impairment extent

$\begin{array}{cc}\text { Complete } & 63.7 \pm 24.7 \\ & (N=66) \\ & \text { Range: } 13-119 \\ \text { Incomplete } & 57.7 \pm 22.6 \\ & (N=93) \\ & \text { Range: } 16-118\end{array}$

Season

Summer

$69.5 \pm 21.4$

$(N=77)$

Range: $32-119$

Winter

$51.5 \pm 21.9^{*}$

$(N=86)$

Range: 13-109

Sport

$\begin{array}{lccc}\text { Outdoor } & 62.5 \pm 22.6 & 73.4 \pm 19.7 & 54.8 \pm 21.3 \\ & (N=116) & (N=48) & (N=68) \\ & \text { Range: } 16-119 & \text { Range: } 37-119 & \text { Range: } 16-109 \\ \text { Indoor } & 53.9 \pm 24.7^{*} & 63.1 \pm 22.9^{*} & 39.1 \pm 20.1^{*} \\ & (N=47) & (N=29) & (N=18) \\ & \text { Range: } 13-117 & \text { Range: } 32-117 & \text { Range: } 13-82\end{array}$

Abbreviations: 25[OH]D, 25-hydroxyvitamin D; NA, not applicable; summer, May to October winter, November to April.

Data presented as mean \pm s.d.

* Significant difference between groups $(P<0.05)$.

\section{DISCUSSION}

Our data showed a high occurrence of vitamin D insufficiency/ deficiency in Swiss elite athletes with a spinal cord injury during the whole year. The occurrence of such insufficient levels was significantly higher during winter months, as well as in indoor sports (Table 1), which has to be taken into account when recommendations in wheelchair sports are made. Vitamin D deficiency increases not only the risk for several diseases ${ }^{15}$ but also the risk for impaired performance. ${ }^{20}$ Therefore, it is very important to check vitamin D status in athletes regularly to maximize the prevention of such a vitamin $\mathrm{D}$ deficiency.

Figure 1 illustrated all individual data points month per month considering the classification of the deficiency. Besides evaluating
Table 3 Occurrence of vitamin D insufficiency/deficiency month per month

\begin{tabular}{lcccc}
\hline Month & $\begin{array}{c}\text { Nondeficient } \\
\text { (N/\%) }\end{array}$ & $\begin{array}{c}\text { Insufficient } \\
\text { (N/\%) }\end{array}$ & $\begin{array}{c}\text { Deficient } \\
\text { (N/\%) }\end{array}$ & $\begin{array}{c}\text { Severely defi- } \\
\text { cient (N/\%) }\end{array}$ \\
\hline January & $2 / 11.1$ & $6 / 33.3$ & $7 / 38.9$ & $3 / 16.7$ \\
February & $1 / 7.1$ & $7 / 50.0$ & $5 / 35.7$ & $1 / 7.1$ \\
March & $4 / 22.2$ & $3 / 16.7$ & $7 / 38.9$ & $4 / 22.2$ \\
April & $5 / 21.7$ & $6 / 26.1$ & $10 / 43.5$ & $2 / 8.7$ \\
May & $3 / 21.4$ & $6 / 42.9$ & $5 / 35.7$ & $0 / 0$ \\
June & $5 / 31.3$ & $9 / 56.3$ & $2 / 12.5$ & $0 / 0$ \\
July & $9 / 47.4$ & $8 / 42.1$ & $2 / 10.5$ & $0 / 0$ \\
August & $7 / 43.8$ & $7 / 43.8$ & $1 / 6.3$ & $1 / 6.3$ \\
September & $2 / 22.2$ & $4 / 44.4$ & $3 / 33.3$ & $0 / 0$ \\
October & $4 / 100.0$ & $0 / 0$ & $0 / 0$ & $0 / 0$ \\
November & $1 / 12.5$ & $2 / 25.0$ & $4 / 50.0$ & $1 / 12.5$ \\
December & $1 / 20.0$ & $3 / 60.0$ & $1 / 20.0$ & $0 / 0$ \\
\hline
\end{tabular}

Abbreviations: $\mathrm{N}$, number of samples; $\%$, percentage of all samples during this month.

individual data over the whole year, one may detect the occurrence of higher vitamin D levels during summer months compared with winter months in this figure as well. In addition, Table 3 shows a higher amount of severely deficient and deficient samples during winter months (January, February and March) compared with the summer months (June, July and August). In $73.2 \%$ of all analyzed samples, $25[\mathrm{OH}] \mathrm{D}$ levels were below $75 \mathrm{nmoll}^{-1}$, which was defined as a reference value for vitamin $\mathrm{D}$ insufficiency. ${ }^{25} \mathrm{~A}$ study investigating the vitamin D status in able-bodied individuals $(n=3276)$ in Switzerland showed a prevalence of $34 \%$ below $38 \mathrm{nmol}^{-1}$ and of $95 \%$ below $95 \mathrm{nmoll}^{-1}$ of the $25[\mathrm{OH}] \mathrm{D} .{ }^{27}$ In addition, another study with unselected, able-bodied patients from Swiss primary care showed a prevalence for vitamin D deficiency of nearly $60 \% .{ }^{28}$ Bauman et al. ${ }^{4}$ found an occurrence of vitamin D deficiency in $32 \%$ of all veterans with a spinal cord injury compared with only $16 \%$ deficiency in their able-bodied controls. Nevertheless, mean serum concentration of $25[\mathrm{OH}] \mathrm{D}$ was not significantly different in these two groups. Our results showed a much higher occurrence of vitamin D insufficiency compared with Bauman et al., ${ }^{4}$ but these authors have defined $16 \mathrm{ngl}^{-1}\left(=\sim 40 \mathrm{nmoll}^{-1}\right)$ as the cutoff for vitamin D deficiency, which is much $<75 \mathrm{nmoll}^{-1}$. Another study ${ }^{5}$ showed an occurrence of $93 \%$ in individuals in an acute inpatient rehabilitation setting for spinal cord injury. The mean concentration for all these subjects was $16.3 \mathrm{ngl}^{-1}$, which corresponds to $40.7 \mathrm{nmoll}^{-1}$. Magee et al. ${ }^{24}$ demonstrated a vitamin D insufficiency/deficiency in 35 and $22 \%$ of their control and supplemented group at baseline measurement in November in a group of Irish elite athletes including paralympians. After supplementation, no insufficient/deficient elite athletes were identified in March, whereas the control group showed a prevalence of $74 \%$ of vitamin D insufficiency/deficiency. To summarize, a vitamin D deficiency in $73.2 \%$ of all samples seems to be very high, but it corresponds to the most common studies investigating vitamin $\mathrm{D}$ levels in individuals with a spinal cord injury. Baumann et al. ${ }^{4}$ described some of the main reasons for such a higher amount of vitamin D-deficient samples in individuals with a spinal cord injury. They mentioned, for example, that patients suffering from a spinal cord injury might be less exposed to sunlight because of immobilization or bedrest. In addition, they might ingest medication, accelerating vitamin $\mathrm{D}$ metabolism. Another reason might involve hypodermal body fat tissue, which impairs the activation of vitamin $\mathrm{D}$ with increasing fat tissue. This issue should not be one of the main factors 
in our elite athletes, as they are mostly highly trained with a high amount of lean mass. Another reason involves covering of skin surface with clothing, which might be higher in individuals with a spinal cord injury because of sensitivity of the skin and altered thermoregulation. In addition, season seems to influence the vitamin $\mathrm{D}$ status in European countries quite dominantly. ${ }^{28}$ Our results showed significantly lower total serum $25[\mathrm{OH}] \mathrm{D}$ concentrations during winter months compared with summer, as well as a higher occurrence of vitamin D insufficiency/deficiency during winter. The same findings were shown for college athletes, ${ }^{29}$ where concentrations were lower during winter and spring compared with fall. Only $15.2 \%$ of these athletes had an optimal vitamin D status during winter. Another study investigating the vitamin D status in healthy girls ${ }^{30}$ showed a $13.4 \%$ prevalence of severe deficiency and a $67.7 \%$ prevalence of deficiency during winter, whereas only $1.6 \%$ showed a deficiency in the next summer. We assume that the occurrence of vitamin D insufficiency/ deficiency in athletes with a spinal cord injury is very similar, if not a little bit higher because of immobility and other factors such as covering of the body surface (see above). Comparing $25[\mathrm{OH}] \mathrm{D}$ concentrations in paralympians measured by Magee et al. ${ }^{24}$ in November and our 'November concentrations', slightly higher values in the Irish population were found $\left(57.9 \mathrm{nmoll}^{-1}\right.$ compared with $\left.48.6 \mathrm{nmol}^{-1}\right)$. Most of their subjects seemed to be standing or more mobile paralympians $(n=21)$, whereas wheelchair-bound paralympians $(n=12)$ showed a baseline concentration in November of $49.2 \mathrm{nmoll}^{-1}$. This concentration of the wheelchair-bound paralympians showed the same result compared with our Swiss elite wheelchair athletes $\left(48.6 \mathrm{nmoll}^{-1}\right)$.

Not only season but also whether the sport was performed indoors or outdoors showed a significant difference. As expected, athletes training and competing mainly outdoors showed a significantly higher vitamin D status compared with indoor athletes (Table 2). Significantly higher values in outdoor sports were shown in college athletes as well. ${ }^{29}$ In addition, a recent meta-analysis calculated a higher risk ratio for vitamin $\mathrm{D}$ inadequacy in indoor sports compared with outdoor. ${ }^{21}$ However, gender, impairment level and extent showed no significant difference during the whole year (Table 2). These results are in line with the outcome of vitamin D levels in patients with a spinal cord injury, where gender, impairment level and extent did not show significant differences during the whole year as well. ${ }^{5}$ Nevertheless, our tetraplegic athletes seem to have significantly lower vitamin D levels during winter months compared with paraplegic athletes (Table 2). Possibly, tetraplegic athletes train mainly indoors during winter or they need to keep their body extremely covered because of the altered thermoregulation caused by the highly lesioned spinal cord injury.

This work is a retrospective data analysis of the yearly medical checkup in our wheelchair elite athletes. Sample size was therefore limited by the number of elite athletes in Switzerland suffering from a spinal cord injury. Nevertheless, compared with other studies with elite athletes, blood data collected from 72 athletes including 164 samples seems to be a very high number for internationally competing elite athletes. Because of training season and competition schedule, it was impossible to standardize the time point of the medical checkup. In October, for example, only four samples have been collected. Nevertheless, we think that this pilot work gives a nice overview concerning the variation of the vitamin $\mathrm{D}$ status during the whole year. For the future, this pilot work showed that an alternative time schedule of blood sampling is needed aiming for samples in October, November and December, and then resampling in spring. We suggest that our athletes with such a new blood-sampling schedule would benefit the most in terms of vitamin D-deficiency prevention during winter months.

\section{CONCLUSION}

We found a relatively high occurrence of vitamin D insufficiency/ deficiency in Swiss elite wheelchair athletes. Such an insufficiency/ deficiency seems to appear more often or to a higher extent during winter and in athletes' training and competing in indoor sports. We recommend checking the vitamin D status in all elite athletes during fall and prescribe supplementation, in case of insufficiency or deficiency.

\section{DATA ARCHIVING}

There were no data to deposit.

\section{CONFLICT OF INTEREST}

The authors declare no conflict of interest.

\section{ACKNOWLEDGEMENTS}

We thank Ruth Heller, Seline Magron and Eliane Arnold-Küng from the Institute of Sports Medicine Nottwil, Switzerland for their help with blood sampling and the laboratory of the Swiss Paraplegic Centre Nottwil for vitamin $\mathrm{D}$ analysis.

1 Carroll A, Onwuneme C, McKenna MJ, Mayne PD, Molloy EJ, Murphy NP. Vitamin D status in Irish children and adolescents: value of fortification and supplementation. Clin Pediatr (Phila) 2014; 53: 1345-1351.

2 Flood-Nichols SK, Tinnemore D, Huang RR, Napolitano PG, Ippolito DL. Vitamin D deficiency in early pregnancy. PLOS ONE 2015; 10: e0123763.

3 Bruyere O, Cavalier E, Souberbielle JC, Bischoff-Ferrari HA, Beaudart C, Buckinx F et al. Effects of vitamin $D$ in the elderly population: current status and perspectives. Arch Public Health 2014; 72: 32.

4 Bauman WA, Zhong YG, Schwartz E. Vitamin D deficiency in veterans with chronic spinal cord injury. Metabolism 1995; 44: 1612-1616.

5 Nemunaitis GA, Mejia M, Nagy JA, Johnson T, Chae J, Roach MJ. A descriptive study on vitamin $D$ levels in individuals with spinal cord injury in an acute inpatient rehabilitation setting. PM R 2010; 2: 202-208.

6 Zhou XJ, Vaziri ND, Segal JL, Winer RL, Eltorai I, Brunnemann SR. Effects of chronic spinal cord injury and pressure ulcer on $25(\mathrm{OH})$-vitamin D levels. J Am Paraplegia Soc 1993; 16: 9-13.

7 Vieth Streym S, Kristine Moller U, Rejnmark L, Heickendorff L, Mosekilde L, Vestergaard $P$. Maternal and infant vitamin D status during the first 9 months of infant life-a cohort study. Eur J Clin Nutr 2013; 67: 1022-1028.

8 Bartoszewska M, Kamboj M, Patel DR. Vitamin D, muscle function, and exercise performance. Pediatr Clin North Am 2010; 57: 849-861.

9 Jaaskelainen T, Knekt P, Suvisaari J, Mannisto S, Partonen T, Saaksjarvi K et al. Higher serum 25-hydroxyvitamin $\mathrm{D}$ concentrations are related to a reduced risk of depression. Br J Nutr 2015; 113: 1418-1426.

10 Jaddou HY, Batieha AM, Khader YS, Kanaan SH, El-Khateeb MS, Ajlouni KM. Depression is associated with low levels of 25-hydroxyvitamin D among Jordanian adults: results from a national population survey. Eur Arch Psychiatry Clin Neurosci 2012; 262: 321-327.

11 Szabo A. Skeletal and extra-skeletal consequences of vitamin D deficiency. Orv Hetil 2011; 152: 1312-1319.

12 Mandarino NR, Junior F, Salgado JV, Lages JS, Filho NS. Is vitamin D deficiency a new risk factor for cardiovascular disease? Open Cardiovasc Med J 2015; 9: 40-49.

13 Beveridge LA, Witham MD. Controversy in the link between vitamin D supplementation and hypertension. Expert Rev Cardiovasc Ther 2015; 13: 1-3.

14 Annweiler C, Rolland Y, Schott AM, Blain H, Vellas B, Herrmann FR et al. Higher vitamin $\mathrm{D}$ dietary intake is associated with lower risk of Alzheimer's disease: a 7-year follow-up. J Gerontol A Biol Sci Med Sci 2012; 67: 1205-1211.

15 Berridge MJ. Vitamin D cell signalling in health and disease. Biochem Biophys Res Commun 2015; 460: 53-71.

16 Wong G, Lim WH, Lewis J, Craig JC, Turner R, Zhu K et al. Vitamin D and cancer mortality in elderly women. BMC Cancer 2015; 15: 106.

17 Kim KJ, Kim YJ, Kim SH, An JH, Yoo HJ, Kim HY et al. Vitamin D status and associated metabolic risk factors among North Korean refugees in South Korea: a crosssectional study. BMJ Open 2015; 5: e009140.

18 Tsugawa N. Bone and Nutrition. Vitamin D intake and bone. Clinical calcium 2015; 25 : 973-981. 
19 Ceglia L, Harris SS. Vitamin D and its role in skeletal muscle. Calcif Tissue Int 2013; 92: $151-162$.

20 Cannell JJ, Hollis BW, Sorenson MB, Taft TN, Anderson JJ. Athletic performance and vitamin D. Med Sci Sports Exerc 2009; 41: 1102-1110.

21 Farrokhyar F, Tabasinejad R, Dao D, Peterson D, Ayeni OR, Hadioonzadeh R et al. Prevalence of vitamin $\mathrm{D}$ inadequacy in athletes: a systematic-review and meta-analysis. Sports Med 2015; 45: 365-378.

22 Bischoff-Ferrari HA, Dawson-Hughes B, Willett WC, Staehelin HB, Bazemore MG, Zee RY et al. Effect of Vitamin D on falls: a meta-analysis. JAMA 2004; 291 1999-2006.

23 Ward KA, Das G, Berry JL, Roberts SA, Rawer R, Adams JE et al. Vitamin D status and muscle function in post-menarchal adolescent girls. J Clin Endocrinol Metab 2009; 94: 559-563.

24 Magee PJ, Pourshahidi LK, Wallace JM, Cleary J, Conway J, Harney E et al. Vitamin D status and supplementation in elite Irish athletes. Int J Sport Nutr Exerc Metab 2013; 23: 441-448.
25 Vieth R. Why the minimum desirable serum 25-hydroxyvitamin $D$ level should be $75 \mathrm{nmol} \mathrm{L}^{-1}\left(30 \mathrm{ng} \mathrm{ml}^{-1}\right)$. Best Pract Res Clin Endocrinol Metab 2011; 25: 681-691.

26 World Medical Association Inc. Declaration of Helsinki. Ethical principles for medical research involving human subjects. J Indian Med Assoc 2009; 107: 403-405.

27 Burnand B, Sloutskis D, Gianoli F, Cornuz J, Rickenbach M, Paccaud F et al. Serum 25-hydroxyvitamin D: distribution and determinants in the Swiss population. Am J Clin Nutr 1992; 56: 537-542.

28 Merlo C, Trummler M, Essig S, Zeller A. Vitamin D deficiency in unselected patients from swiss primary care: a cross-sectional study in two seasons. PLOS ONE 2015; 10: e0138613.

29 Halliday TM, Peterson NJ, Thomas JJ, Kleppinger K, Hollis BW, Larson-Meyer DE. Vitamin D status relative to diet, lifestyle, injury, and illness in college athletes. Med SCi Sports Exerc 2011; 43: 335-343.

30 Lehtonen-Veromaa M, Mottonen T, Irjala K, Karkkainen M, Lamberg-Allardt C, Hakola P et al. Vitamin $D$ intake is low and hypovitaminosis $D$ common in healthy 9 - to 15-year-old Finnish girls. Eur J Clin Nutr 1999; 53: 746-751. 